\title{
Development of Empirical Correlation for Thermal Fatigue Life Cycle Prediction
}

\author{
Nirajkumar Mehta, Komal Mehta, Dipesh Shukla, Prasun Chakrabarti
}

\begin{abstract}
Furnaces are most commonly used for melting of Iron and its various alloy materials. Induction furnaces are using electric power supply so they are more beneficial as no fuel is required. It is an extremely critical to find life span or life cycle of Induction Melting Furnace Wall under thermal load change conditions. The low cycle thermal fatigue life time $L$ is depended upon various parameters like thickness of induction furnace refractory wall $t$, density of refractory material $\bar{\rho}$, inside film co-efficient $\widehat{h}_{\mathrm{I}}$ outside film co efficient $\widehat{h}_{0}$, thermal expansion coefficient $\alpha$, inside temperature $\mathrm{T}_{\mathrm{I}}$,outside temperature $\overline{\mathrm{T}_{0}}$, specific heat of refractory material $C$, elasticity constant $E$, ultimate strength $S$, thermal conductivity of refractory material $k$, Volume $V$, time period of melting cycle $\tau$. An expression for thermal fatigue life time of induction furnace melting wall is derived by dimensional analysis using bunkingham's $\pi$ theorem. Then the empirical correlation is derived from the data available from theory as well as experimental and numerical results.
\end{abstract}

Keywords: - Induction Furnace, Heat Transfer, Empirical Correlation, Life Cycle Prediction

\section{INTRODUCTION}

The furnace is a system used for melting the metals for casting or heating of materials to changing form and its size like rolling, forging etc. It is also used for change any material properties of the metals like annealing or normalizing processes. Generally, furnace is assessed into two types in keeping with generating approach of heat. It is combustion type and electric kind. In combustion kind of furnace usually used as fuel is oil and coal. Then electric type furnace known as induction furnace. If we want to solve heat transfer and thermal fatigue problems involving simple geometries with effortless boundary circumstance. It is solved by using analytical procedure but whilst it is intricated boundary circumstance than we cannot solve analytically. There are numerous approaches to obtains the numerical process of heat transfer problem consisting of finite difference approach, finite element method and boundary element approach.

\section{LITERATURE SURVEY}

The study on the distribution rule of temperature and thermal stress distribution and on the fatigue life comparison process for the refractory wall

Revised Manuscript Received on March 15, 2020.

Nirajkumar Mehta, Associate Professor, ITM Universe, Vadodara, Gujarat, India. India.

Komal Mehta, Associate Professor, ITM Universe, Vadodara, Gujarat,

Dipesh Shukla, Director, Amity University, Jaipur, Rajasthan, India.

Prasun Chakrabarti, Institute Distinguished Senior Chair Professor, Techno India NJR Institute of Technology, Udaipur, India.
Is not going to lay foundation for the improvement acquaintance of on the thermal fatigue of this form of elements underneath thermal shock conditions of low cycle and excessive phase transition stresses but in addition presents amazing management for thermal fatigue failure.

A complete literature assessment on computational investigation on one of a kind of variety of furnaces is completed to be trained study trends. An overview is done on applications of distinct numerical approaches in heat transfer with its applications. Thermal fatigue evaluation of induction melting furnace wall is done for silica ramming mass. An evaluation is completed for study on induction heating. A evaluate is finished for metal forming analysis utilizing exceptional numerical approaches. Transient heat transfer analysis of induction furnace is done through utilizing finite detail evaluation. Thermal fatigue evaluation of induction furnace wall is finished for alumina ramming mass. Thermal evaluation of scorching wall condenser is done for home refrigerator using numerical process for temperature distribution. Optimization of wall thickness for minimal heat loss for induction furnace wall via finite detail evaluation. An assessment is finished on numerical evaluation of furnace. Thermal fatigue analysis of induction furnace refractory wall is finished for zirconia. Comparison of finite difference system and finite detail procedure is finished for $2 \mathrm{D}$ transient heat switch predicament. Thermal fatigue analysis of induction furnace wall is completed for magnesia ramming mass. Evolved mathematical modelling of heat transfer is finished for induction furnace wall of zirconia. Advanced heat transfer analysis is completed for alumina based refractory wall of induction furnace. Also, specific Finite change procedure is used to find out temperature and thermal stress difference with respect to time. [1-38]

\section{DEVELOPMENT OF EMPIRICAL CORRELATION}

The functional relationship can be written is the following format.

$\mathrm{L}=\mathrm{f}\left(\mathrm{t}, \rho, h_{i}\left|h_{n},\right| \alpha_{1}\left|T_{i},\right| T_{n}, \mathrm{C}, \mathrm{E}, \mathrm{S}, \mathrm{k}, \tau, \mathrm{V}\right)$

Its general format becomes as following.

$\mathrm{F}\left(\mathrm{L}, \mathrm{t}, \overline{\rho, h_{i}}, \sqrt{h_{n}}, \sqrt{\alpha}, \sqrt{T_{i}}, \bar{T}_{n}, \mathrm{C}, \mathrm{E}, \mathrm{S}, \mathrm{k}, \tau, \mathrm{V}\right)=0$

Here, number of variables $n=14$

Number of fundamental quantity $\mathrm{m}=4$

No. of $\pi$ terms $=n-m=14-4=10$.

Repeating variables:

1. geometry property $-\mathrm{t}$

2. thermal property $-\mid T_{i}$

3. fluid property $-\bar{\rho}$

4. time variable $-\tau$

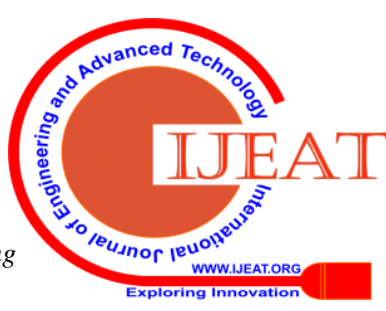




\section{Development of Empirical Correlation for Thermal Fatigue Life Cycle Prediction}

\begin{tabular}{l}
$\pi_{1}=t^{a 1} T_{i}^{b 1} \rho^{c 1} \tau^{d 1} k$ \\
\hline$\pi_{2}=t^{a 2} T_{i}^{b 2} \rho^{c 2} \tau^{d 2} h_{i}$ \\
\hline$\pi_{3}=t^{a 3} T_{i}^{b 3} \rho^{c 3} \tau^{d 3} a$ \\
\hline$\pi_{4}=t^{a 4} T_{i}^{b 4} \rho^{c 4} \tau^{d 4} E$ \\
\hline$\pi_{5}=t^{a 5} T_{i}^{b 5} \rho^{c 5} \tau^{d 5} c$ \\
$\pi_{6}=t^{a 6} T_{i}^{b 6} \rho^{c 6} \tau^{d 6} L$ \\
\hline$\pi_{7}=t^{a 7} T_{i}^{b 7} \rho^{c 7} \tau^{d 7} T_{o}$ \\
\hline$\pi_{8}=t^{a 8} T_{i}^{b 8} \rho^{c 8} \tau^{d 8} S$ \\
\hline$\pi_{9}=t^{a 9} T_{i}^{b 9} \rho^{c 9} \tau^{d 9} h_{o}$ \\
\hline$\pi_{10}=t^{a 10} T_{i}^{b 10} \rho^{c 10} \tau^{d 10} V$
\end{tabular}

Dimensions of different quantities are as per following.

$\mathrm{L} \Rightarrow \mathrm{M}^{0} \mathrm{~L}^{0} \mathrm{~T}^{1} \mathrm{~K}^{0}, \boldsymbol{\rho} \Rightarrow \mathrm{M}^{1} \mathrm{~L}^{-3} \mathrm{~T}^{0} \mathrm{~K}^{0}, \mathrm{k} \Rightarrow \mathrm{M}^{1} \mathrm{~L}^{1} \mathrm{~T}^{-3} \mathrm{~K}^{-1}$, $\sqrt{h_{i}} \Rightarrow>\mathrm{M}^{1} \mathrm{~L}^{0} \mathrm{~T}^{-3} \mathrm{~K}^{-1}, \mathrm{C} \Rightarrow \mathrm{M}^{1} \mathrm{~L}^{2} \mathrm{~T}^{-2} \mathrm{~K}^{-1}, \overline{T_{i}} \Rightarrow>\mathrm{M}^{0} \mathrm{~L}^{0} \mathrm{~T}^{0} \mathrm{~K}^{1}$, $T_{n} \Rightarrow \mathrm{M}^{0} \mathrm{~L}^{0} \mathrm{~T}^{0} \mathrm{~K}^{1}, \mathrm{t} \Rightarrow \mathrm{M}^{0} \mathrm{~L}^{1} \mathrm{~T}^{0} \mathrm{~K}^{0}, h_{n} \Rightarrow \mathrm{M}^{1} \mathrm{~L}^{0} \mathrm{~T}^{-3} \mathrm{~K}^{-1}, \mid \boldsymbol{a}$ $\Rightarrow \mathrm{M}^{0} \mathrm{~L}^{1} \mathrm{~T}^{0} \mathrm{~K}^{-1}, \mathrm{E} \Rightarrow \mathrm{M}^{1} \mathrm{~L}^{-1} \mathrm{~T}^{-2} \mathrm{~K}^{0}, \tau \Rightarrow \mathrm{M}^{0} \mathrm{~L}^{0} \mathrm{~T}^{1} \mathrm{~K}^{0}, \mathrm{~S} \Rightarrow$ $\mathrm{M}^{1} \mathrm{~L}^{-1} \mathrm{~T}^{-2} \mathrm{~K}^{0}, \mathrm{~d} \Rightarrow \mathrm{M}^{0} \mathrm{~L}^{3} \mathrm{~T}^{0} \mathrm{~K}^{0}$

Now 10 different $\pi$ terms are derived from dimensional analysis.

1. $\pi_{1}=t^{a 1} T_{i}^{b 1} \rho^{c 1} \tau^{d 1} k$

$\pi_{1}=\mathrm{M}^{0} \mathrm{~L}^{0} \mathrm{~T}^{0} \mathrm{~K}^{0}=[\mathrm{L}]^{\mathrm{a} 1}[\mathrm{~K}]^{\mathrm{b} 1}\left[\mathrm{ML}^{-3}\right]^{\mathrm{c} 1}[\mathrm{~T}]^{\mathrm{d} 1}\left[\mathrm{M}^{1} \mathrm{~L}^{1} \mathrm{~T}^{-3} \mathrm{~K}^{-1}\right]$

Power of M: $0=\mathrm{c} 1+1, \mathrm{c} 1=-1$

Power of L: $0=\mathrm{a} 1-3 \mathrm{c} 1+1, \mathrm{a} 1-3(-1)+1=0$, a $1=-4$

Power of T: $0=\mathrm{d} 1-3, \mathrm{~d} 1=3$

Power of K: $0=\mathrm{b} 1-1, \mathrm{~b} 1=1$

$\sqrt{\pi_{1}}=\sqrt{\frac{T_{i} k \tau^{2}}{\rho t^{4}}}$

2. $\pi_{2}=t^{a 2} T_{i}^{b 2} \rho^{c 2} \tau^{d 2} h_{i}$

$\pi_{2}=\mathrm{M}^{0} \mathrm{~L}^{0} \mathrm{~T}^{0} \mathrm{~K}^{0}=[\mathrm{L}]^{\mathrm{a} 2}[\mathrm{~K}]^{\mathrm{b} 2}\left[\mathrm{ML}^{-3}\right]^{\mathrm{c} 2}[\mathrm{~T}]^{\mathrm{d} 2}\left[\mathrm{M}^{1} \mathrm{~L}^{0} \mathrm{~T}^{-3} \mathrm{~K}^{-1}\right]$

Power of M: $0=\mathrm{c} 2+1, \mathrm{c} 2=-1$

Power of L: $0=\mathrm{a} 2-3 \mathrm{c} 2, \mathrm{a} 2-3(-1)=0, \mathrm{a} 2=-3$

Power of T: $0=\mathrm{d} 2-3, \mathrm{~d} 2=3$

Power of $\mathrm{K}: 0=\mathrm{b} 2-1, \mathrm{~b} 2=1$

$\pi \pi_{2}=\frac{T_{I} h_{I} \tau^{3}}{\rho t^{3}}$

$3 . \pi_{3}=t^{a 3} T_{i}^{b 3} \rho^{c 3} \tau^{d 3} \alpha$

$\pi_{3}=\mathrm{M}^{0} \mathrm{~L}^{0} \mathrm{~T}^{0} \mathrm{~K}^{0}=[\mathrm{L}]^{\mathrm{a} 3}[\mathrm{~K}]^{\mathrm{b} 3}\left[\mathrm{ML}^{-3}\right]^{\mathrm{c} 3}[\mathrm{~T}]^{\mathrm{d} 3}\left[\mathrm{M}^{0} \mathrm{~L}^{1} \mathrm{~T}^{0} \mathrm{~K}^{-1}\right]$

Power of $\mathrm{M}: 0=\mathrm{c} 3, \mathrm{c} 3=0$

Power of L: $0=\mathrm{a} 3-3 \mathrm{c} 3+1, \mathrm{a} 3-3(0)+1=0, \mathrm{a} 3=-1$

Power of T: $0=\mathrm{d} 3, \mathrm{~d} 3=0$

Power of $\mathrm{K}: 0=\mathrm{b} 3-1, \mathrm{~b} 3=1$

$\pi_{3}=\frac{\mathrm{T}_{\mathrm{I}} \mathrm{a}}{\mathrm{t}}$

4. $\pi_{4}=t^{a 4} T_{i}^{b 4} \rho^{c 4} \tau^{d 4} E$

$\pi_{4}=\mathrm{M}^{0} \mathrm{~L}^{0} \mathrm{~T}^{0} \mathrm{~K}^{0}=[\mathrm{L}]^{\mathrm{a} 4}[\mathrm{~K}]^{\mathrm{b} 4}\left[\mathrm{ML}^{-3}\right]^{\mathrm{c} 4}[\mathrm{~T}]^{\mathrm{d} 4}\left[\mathrm{M}^{1} \mathrm{~L}^{-1} \mathrm{~T}^{-2} \mathrm{~K}^{0}\right]$

Power of $\mathrm{M}: 0=\mathrm{c} 4+1, \mathrm{c} 4=-1$

Power of L: $0=\mathrm{a} 4-3 \mathrm{c} 4-1, \mathrm{a} 4-3(-1)-1=0, \mathrm{a} 4=-2$

Power of T: $0=\mathrm{d} 4-2, \mathrm{~d} 4=2$

Power of K: $0=\mathrm{b} 4, \mathrm{~b} 4=0$

$\pi_{4}=\frac{E \tau^{2}}{\rho t^{2}}$

5. $\pi_{5}=t^{a 5} T_{i}^{b 5} \rho^{c 5} \tau^{d 5} C$

$\pi_{5}=\mathrm{M}^{0} \mathrm{~L}^{0} \mathrm{~T}^{0} \mathrm{~K}^{0}=[\mathrm{L}]^{\mathrm{a} 5}[\mathrm{~K}]^{\mathrm{b} 5}\left[\mathrm{ML}^{-3}\right]^{\mathrm{c} 5}[\mathrm{~T}]^{\mathrm{d} 5}\left[\mathrm{M}^{1} \mathrm{~L}^{2} \mathrm{~T}^{-2} \mathrm{~K}^{-1}\right]$

Power of M: $0=\mathrm{c} 5+1, \mathrm{c} 5=-1$

Power of L: $0=\mathrm{a} 5-3 \mathrm{c} 5-1$, a5 $-3(-1)+2=0$, a $5=-5$

Power of T: $0=\mathrm{d} 5-2, \mathrm{~d} 5=2$

Power of $\mathrm{K}: 0=\mathrm{b} 5-1, \mathrm{~b} 5=1$

$\pi_{5}=\frac{T_{i} C \tau^{2}}{\rho t^{5}}$
$6 . \pi_{6}=t^{a 6} T_{i}^{b 6} \rho^{c 6} \tau^{d 6} L$
$\pi_{6}=\mathrm{M}^{0} \mathrm{~L}^{0} \mathrm{~T}^{0} \mathrm{~K}^{0}=[\mathrm{L}]^{\mathrm{a} 6}[\mathrm{~K}]^{\mathrm{b} 6}\left[\mathrm{ML}^{-3}\right]^{\mathrm{c} 6}[\mathrm{~T}]^{\mathrm{d} 6}\left[\mathrm{M}^{0} \mathrm{~L}^{0} \mathrm{~T}^{1} \mathrm{~K}^{0}\right]$

Power of M: $0=\mathrm{c} 6, \mathrm{c} 6=0$

Power of L: $0=\mathrm{a} 6-3 \mathrm{c} 6, \mathrm{a} 6-3(0)=0, \mathrm{a} 6=0$

Power of T: $0=\mathrm{d} 6+1, \mathrm{~d} 6=-1$

Power of $\mathrm{K}: 0=\mathrm{b} 6, \mathrm{~b} 6=0$

$\pi_{6}=\frac{L}{\tau}$

7. $\pi_{7}=t^{a 7} T_{i}^{b 7} \rho^{c 7} \tau^{d 7} T_{o}$

$\pi_{7}=\mathrm{M}^{0} \mathrm{~L}^{0} \mathrm{~T}^{0} \mathrm{~K}^{0}=[\mathrm{L}]^{\mathrm{a} 7}[\mathrm{~K}]^{\mathrm{b} 7}\left[\mathrm{ML}^{-3}\right]^{\mathrm{c} 7}[\mathrm{~T}]^{\mathrm{d} 7}\left[\mathrm{M}^{0} \mathrm{~L}^{0} \mathrm{~T}^{0} \mathrm{~K}^{1}\right]$

Power of M: $0=\mathrm{c} 7, \mathrm{c} 7=0$

Power of L: $0=\mathrm{a} 7-3 \mathrm{c} 7, \mathrm{a} 7-3(0)=0, \mathrm{a} 7=0$

Power of T: $0=\mathrm{d} 7, \mathrm{~d} 7=0$

Power of $\mathrm{K}: 0=\mathrm{b} 7+1, \mathrm{~b} 7=-1$

$\pi_{7}=\frac{\mathrm{T}_{\mathrm{c}}}{\mathrm{T}_{\mathrm{i}}}$

$8 . \pi_{8}=t^{a 8} T_{i}^{b 8} \rho^{c 8} \tau^{d 8} S$

$\pi_{8}=\mathrm{M}^{0} \mathrm{~L}^{0} \mathrm{~T}^{0} \mathrm{~K}^{0}=[\mathrm{L}]^{\mathrm{a} 8}[\mathrm{~K}]^{\mathrm{b} 8}\left[\mathrm{ML}^{-3}\right]^{\mathrm{c} 8}[\mathrm{~T}]^{\mathrm{d} 8}\left[\mathrm{M}^{1} \mathrm{~L}^{-1} \mathrm{~T}^{-2} \mathrm{~K}^{0}\right]$

Power of M: $0=\mathrm{c} 8+1, \mathrm{c} 8=-1$

Power of L: $0=\mathrm{a} 8-3 \mathrm{c} 8-1, \mathrm{a} 8-3(-1)-1=0, \mathrm{a} 8=-2$

Power of T: $0=\mathrm{d} 8-2, \mathrm{~d} 8=2$

Power of K: $0=\mathrm{b} 8, \mathrm{~b} 8=0$

$\pi_{8}=\frac{S \tau^{2}}{\rho t^{2}}$

9. $\pi_{9}=t^{a 9} T_{i}^{b 9} \rho^{c 9} \tau^{d 9} h_{c}$ $\pi_{\mathrm{g}}=\mathrm{M}^{0} \mathrm{~L}^{0} \mathrm{~T}^{0} \mathrm{~K}^{0}=[\mathrm{L}]^{\mathrm{a} 9}[\mathrm{~K}]^{\mathrm{b} 9}\left[\mathrm{ML}^{-3}\right]^{\mathrm{c} 9}[\mathrm{~T}]^{\mathrm{d} 9}\left[\mathrm{M}^{1} \mathrm{~L}^{0} \mathrm{~T}^{-3} \mathrm{~K}^{-1}\right]$

Power of M: $0=\mathrm{c} 9+1, \mathrm{c} 9=-1$

Power of L: $0=\mathrm{a} 9-3 \mathrm{c} 9$, a $9-3(-1)=0$, a9 $=-3$

Power of T: $0=\mathrm{d} 9-3, \mathrm{~d} 9=3$

Power of $\mathrm{K}: 0=\mathrm{b} 9-1, \mathrm{~b} 9=1$

$\pi \pi_{9}=\frac{T_{I} h_{0} \tau^{3}}{0 t^{3}}$

$10 . \pi_{10}=t^{a 10} T_{i}^{b 10} \rho^{c 10} \tau^{d 10} \mathrm{~V}$

$\pi_{1 \mathrm{n}}=\mathrm{M}^{0} \mathrm{~L}^{0} \mathrm{~T}^{0} \mathrm{~K}^{0}=[\mathrm{L}]^{\mathrm{a} 10}[\mathrm{~K}]^{\mathrm{b} 10}\left[\mathrm{ML}^{-3}\right]^{\mathrm{c} 10}[\mathrm{~T}]^{\mathrm{d} 10}\left[\mathrm{M}^{0} \mathrm{~L}^{3} \mathrm{~T}^{0} \mathrm{~K}^{0}\right]$

Power of M: $0=\mathrm{c} 10, \mathrm{c} 10=0$

Power of L: $0=\mathrm{a} 10-3 \mathrm{c} 10+3, \mathrm{a} 10-3(0)+3=0, \mathrm{a} 10=-3$

Power of T: $0=\mathrm{d} 10, \mathrm{~d} 10=0$

Power of K: $0=b 10, b 10=0$

$\pi_{10}=\frac{V}{t^{3}}$

Now, it is possible to write functional relationship as following.

$\mathrm{F}\left(\sqrt{\pi_{1}}, \sqrt{\pi_{2}}, \sqrt{\pi_{3}}, \sqrt{\pi_{4}, \pi_{5}}, \sqrt{\pi_{6}, \pi_{7}}, \sqrt{\pi_{8}, \pi_{9}}, \sqrt{\left.\pi_{10}\right)}=0\right.$

$f\left(\frac{T_{I} k \tau^{3}}{\rho t^{4}}, \frac{T_{I} h_{I} \tau^{3}}{\rho t^{3}}, \frac{T_{I} \alpha}{t}, \frac{E \tau^{2}}{\rho t^{2}}, \frac{T_{I} C \tau^{2}}{\rho t^{5}}, \frac{L}{\tau}, \frac{T_{0}}{T_{I}}, \frac{S \tau^{2}}{\rho t^{2}}, \frac{T_{I} h_{o} \tau^{3}}{\rho t^{3}}, \frac{V}{t^{3}}\right)=$ 0

$L=\tau \varphi\left(\frac{T_{I} k \tau^{3}}{\rho t^{4}}, \frac{T_{I} h_{I} \tau^{3}}{\rho t^{3}}, \frac{T_{I} \alpha}{t}, \frac{E \tau^{2}}{\rho t^{2}}, \frac{T_{I} C \tau^{2}}{\rho t^{5}}, \frac{T_{0}}{T_{I}}, \frac{S \tau^{2}}{\rho t^{2}}, \frac{T_{I} h_{o} \tau^{3}}{\rho t^{3}}, \frac{V}{t^{3}}\right)$

From experimental results and rational analysis, the empirical correlation is derived here to find out thermal fatigue life cycle of induction melting furnace refractory wall.

$$
L=\mathrm{K} \frac{h_{o} S}{h_{i} E}\left(\frac{\rho t^{3}}{\alpha T_{i} T_{o} V \tau^{2}}\right)^{1.5}\left(\frac{\rho t^{2}}{E \tau^{2}}\right)^{1.7}
$$





\section{Development of Empirical Correlation for Thermal Fatigue Life Cycle Prediction}

Table 1 Comparison of Numerical results with Empirical Correlation

\begin{tabular}{|c|c|c|c|c|c|}
\hline Materials & Silica & Alumina & Magnesia & Zirconia & Unit \\
\hline $\begin{array}{c}\text { Internal Film Co-efficient } \\
\text { hi }\end{array}$ & 200 & 200 & 200 & 200 & $\mathrm{~W} / \mathrm{m}^{2} \mathrm{~K}$ \\
\hline $\begin{array}{c}\text { External Film } \\
\text { Co-efficient ho }\end{array}$ & 40 & 40 & 40 & 40 & $\mathrm{~W} / \mathrm{m}^{2} \mathrm{~K}$ \\
\hline Thickness of wall & 0.12 & 0.12 & 0.12 & 0.12 & $\mathrm{~m}$ \\
\hline Volume & 3000 & 3000 & 3000 & 3000 & $\mathrm{~m}^{3}$ \\
\hline Density & 2800 & 3400 & 3300 & 5000 & $\mathrm{Kg} / \mathrm{m}^{3}$ \\
\hline Time Interval $\Delta \mathrm{t}$ & 10 & 10 & 10 & 10 & $\mathrm{Seconds}$ \\
\hline Thermal Conductivity k & 1.7 & 2.6 & 4 & 1.2 & $\mathrm{~W} / \mathrm{m} \mathrm{K}$ \\
\hline $\begin{array}{c}\text { Temperature outside } \\
\text { Furnace Wall }\end{array}$ & 303 & 303 & 303 & 303 & $\mathrm{Kelvin}$ \\
\hline $\begin{array}{c}\text { Temperature inside } \\
\text { Furnace Wall }\end{array}$ & 1673 & 1873 & 1773 & 1873 & $\mathrm{Kelvin}$ \\
\hline Specific Heat & 950 & 920 & 880 & 780 & $\mathrm{~J} / \mathrm{kg} \mathrm{K}$ \\
\hline Elasticity Constant & 0.19 & 0.232 & 0.19 & 0.26 & $\mathrm{~N} / \mathrm{m}^{2}$ \\
\hline $\begin{array}{c}\text { Thermal Expansion } \\
\text { Co-efficient }\end{array}$ & 0.00000139 & 0.00000098 & 0.00000153 & 0.00000097 & $\mathrm{~m} / \mathrm{K}$ \\
\hline Ultimate Stress & 500 & 500 & 600 & 600 & $\mathrm{Mpa}$ \\
\hline Answer of Equation & 0.000207105 & 0.000320594 & 0.000333716 & 0.000982126 & $\mathrm{NA}$ \\
\hline $\begin{array}{c}\text { Constant } \\
\text { Empirical Correlation } \\
\text { Answer }\end{array}$ & 1080000 & 1080000 & 1080000 & 1080000 & $\mathrm{NA}$ \\
\hline $\begin{array}{c}\text { Computer Program } \\
\text { Results }\end{array}$ & 223.673555 & 346.2413801 & 360.413173 & 1060.696335 & Cycles \\
\hline \begin{tabular}{c} 
\% Error \\
\hline
\end{tabular} & $-4 \%$ & $-0.2 \%$ & $0.006 \%$ & $-6.7 \%$ & $\mathrm{Cycles}$ \\
\hline
\end{tabular}

Comparison of numerical results with developed empirical correlation is given in Table 1. This Empirical Correlation will be known as Shukla-Mehta's Correlation and Constant will be known as Shukla-Mehta's Constant which is having value 1080000 . Shukla-Mehta's Correlation can predict the life cycle of induction furnace wall for diverse refractory materials.

Percentage of Error in the results of Shukla-Mehta's Correlation for silica ramming mass is $-4 \%$, for alumina ramming mass is $-0.2 \%$, for magnesia ramming mass is 0.06 $\%$ and for zirconia $-6.7 \%$. Shukla-Mehta's Correlation can predict life cycle of any refractory material with + or $-10 \%$ error with compare to numerical results. Because of many miscellaneous factors involved in thermal fatigue life cycle prediction of induction furnace wall, this limit can be considered acceptable. If zirconia is neglected as special refractory and not used practically then prediction error can be + or $-5 \%$ only.

\section{CONCLUSION}

An empirical correlation is invented by dimensional analysis and rational analysis which is proficient of directly prediction life cycle of the induction furnace wall for any refractory material and any capacity of furnace. Several dimensionless numbers are established using different quantities which are considered as significance parameters of life cycle for induction furnace wall. Then rational analysis is done for finding out precise correlation using investigational figures available from industries. This results in a very advanced investigation work as it will open up pioneering entryways for thermal fatigue life prediction arena.
This empirical correlation can be even modified and tailored to solve many miscellaneous thermal fatigue life problems in the field of mechanical engineering. Life cycle can also be found out with diverse probability to justify the miscellaneous behavior. Empirical correlation established is extremely valuable because with the use of its life cycle can be effortlessly and accurately predicted by simple data of material properties and geometrical features. This research will be supportive in solving countless complex thermal fatigue problems worldwide.

\section{REFERENCES}

1. H, Kohne R, Nitsch J, Sprengel U, Solar thermal powerplants for solar countries-technology, economics and market potential, Applied Energy 52(2-3), 1995; 165-83.

2. Mancini TR, Kolb GJ, Chavez JM, Solar thermal power today and tomorrow, Mech. Engg., 116(8), 1994, 74-9.

3. Ravi Kumar K, Reddy KS, Thermal analysis of solar parabolic trough with porous disc receiver. Applied Energy 86(9), 2009, 1804-12.

4. Vanita Thakkar, Status of Parabolic Dish Solar Concentrators, International Journal of Enhanced Research in Science Technology \& Engineering Vol. 2 Issue 6, June-2013, pp - 42-50

5. S. A. Kalogirou, Solar thermal collectors and applications. Prgress in Energy and Combustion Science, 2004. 30: p. 231-295.

6. Australian Energy Resource Asssessment, Solar Energy.

7. A. Sazena and S. Ghanshyam, Performance studies of a multipurpose solar Energy System for Remote areas. MIT International Journal of Mchanical Engineering, 2013. 3(1): p. 21-33

8. S. A. Kalogirou, Solar thermal collectors and applications. Prgress in Energy and Combustion Science, 2004. 30: p. 231-295. 


\section{Development of Empirical Correlation for Thermal Fatigue Life Cycle Prediction}

9. B.SriHariPriya, R.SantoshiKumari, M.TukaramBai, V.Sridevi, Review on Water Desalination using Renewable Solar Energy. IJIRST -International Journal for Innovative Research in Science \& Technology| Volume 2 | Issue 07 | December 2015.

10. Philippe SCHILD,European Commission on Concentrated Solar Thermal Energy, Office CDMA 5-141,B-1049 Brussels.

11. M. Ouannene, B. Chaouachi, S.Gabsi, design and realisation of a parabolic solar cooker. National School of Engineers of Gabes (E.N.I.G) - Omar IbnElKhattab Street -6029 Gabes-Tunisia.

12. Nirajkumar Mehta, (May 2012), Review on Computational Investigation on Different Kinds of Furnaces, International Conference on Emerging Technologies and Applications in Engineering, Technology and Sciences, Volume 3, pp $1-7$.

13. S. O. Jimoh (2013), analysis of the characteristics of the blast furnaces peripherical zone, international journal of science and technology research

14. N C Mehta, Vipul B Gondaliya, Jayesh V Gundaniya, (February 2013), Applications of Different Numerical Methods in Heat Transfer - A Review, International Journal of Emerging Technology and Advanced Engineering, Volume 3, Issue 2, pp 363 - 368.

15. Camilolezcano (2013), Numerical calculation of the recirculation factor in flameless furnaces, ISSN 0012-7353, pp 144-151.

16. N C Mehta, Viral V Shiyani, Jemish R Nasit, (May 2013), Metal Forming Analysis, International Journal of Emerging Technology and Advanced Engineering, Volume 3, Issue 5, pp 190 - 196.

17. Vipul Gondaliya, Mehul Pujara, Nirajkumar Mehta, (August 2013), Transient Heat Transfer Analysis of Induction Furnace by Using Finite Element Analysis, International Journal of Applied Research, Volume 3 , Issue 8 , pp $231-234$.

18. N C Mehta, Vasim G Machhar, Ravi K Popat, (October 2013), Thermal Fatigue Analysis of Induction Furnace Wall for Alumina ramming mass, International Journal of Science and Engineering Applications, Volume 2, Issue 10, pp 186 - 190, DOI 10.7753/IJSEA0210.1002.

19. Gaurav Kumar Thakur (2013), Analysis of fuel injection in blast furnaces with the help of CFD software approach, international journal of scientific and research publication, volume 3 , issue 3, ISSN 2250-3153, page no-1-7.

20. N C Mehta, Akash D Raiyani, Vikas R Gondalia, (February 2013), Thermal Fatigue Analysis of Induction Melting Furnace Wall for Silica ramming mass, International Journal of Emerging Technology and Advanced Engineering, Volume 3, Issue 2, pp 357 - 362.

21. Vimal R Nakum, Kevin M Vyas, Niraj C Mehta, (April 2013), Research on Induction Heating - A Review, International Journal of Science and Engineering Applications, Volume 2, Issue 6, pp 141 144, DOI: 10.7753/IJSEA0206.1005.

22. Andrey V Gil (2015), Research of integral parameters for furnaces of a circulating fluidized bed, EDP publication science, EPJ web of conference 82,01044, page no-01044-p.1-01044-p.5.

23. Nirajkumar C Mehta, Dipesh D Shukla, Ravi K Popat, (December 2014), Optimization of Wall Thickness for Minimum Heat Loss for Induction Furnace by FEA, Indian Foundry Journal, Volume 60, No. 12, pp 19-25.

24. Nirajkumar C Mehta, Dr. Dipesh D Shukla, Vishvash B Rajyaguru, (April 2015), Numerical Analysis of Furnace: Review, National Conference on Recent Research and Development in Core Disciplines of Engineering, Vadodara, Volume: 2, pp 1 -7.

25. Nirajkumar C Mehta, Dr. Dipesh D Shukla, Vishvash B Rajyaguru, (April 2015), Thermal Fatigue Analysis of Induction Furnace Wall for Zirconia, National Conference on Recent Research and Development in Core Disciplines of Engineering, Vadodara, Volume: 2, pp 1 - 6.

26. Nirajkumar C Mehta, Dr. Dipesh D Shukla, Pragnesh D Kandoliya, (April 2015), Comparison of Finite Difference Method and Finite Element Method for 2 D Transient Heat Transfer Problem, National Conference on Recent Research and Development in Core Disciplines of Engineering, Vadodara, Volume: 2, pp $1-10$.

27. Saheedlekangbad Mosi (2015), Effect of steel plants with three-phase induction furnaces on power distribution quality of the existing $33 \mathrm{kv}$ network in Nigeria, advance in science and technology research journal, volume 9, no.27, pages 1-10.

28. Nirajkumar C Mehta, Dr. Dipesh D Shukla, (June 2015), Thermal Fatigue Analysis of Induction Furnace Wall for Magnesia Ramming Mass, ASME 2015 Applied Mechanics and Materials Conference, At Seattle, Washington, United States of America, Volume: 12, pp $1-6$.

29. Nirajkumar C Mehta, Dr. Dipesh D Shukla, Pragnesh D Kandoliya, (December 2016), Advanced Mathematical Modeling of Heat Transfer in Induction Furnace Wall of Zirconia, International Journal of
Engineering Research and Technology, Volume 5, Issue 10, pp 176 181, DOI: 10.17577/IJERTV5IS120128

30. Nirajkumar C Mehta, Dr. Dipesh D Shukla, Pragnesh D Kandoliya, (December 2016), Advanced Heat Transfer Analysis of Alumina Based Refractory Wall of Induction Furnace, National Conference on Emerging Trends in Engineering, Volume 1, pp $1-6$.

31. Piotr Bulinski (2016), coupled numerical model of metal melting in an induction furnace: sensitivity analysis and validation of model, Silesian university of technology, institute of thermal technology and Silesian university of technology, department of industrial informatics, ISSN 0033-2097

32. Mirko Filipponi (2016), thermal analysis of an industrial furnace, MDPI Energies, 2016, 9, 833, 1-30.

33. Prof. Nirajkumar C. Mehta, Dr. Dipesh D. Shukla, (December 2017) Mathematical Modelling for Life Cycle Forecasting of Zirconia Based Furnace Wall, International Journal of Advance Research and Innovative Ideas in Education, IJARIIE, ISSN(O)-2395-4396, Vol-3 Issue-4 2017, pp 796-807.

34. Nirajkumar C Mehta, Dr. Dipesh D Shukla, Stress analysis of induction furnace wall for magnesia ramming mass, Journal of Metallurgy and Materials Science, Volume: 59, Issue: 2, pp. 85-110, Print ISSN: 0972-4257. Online ISSN: 0974-1267, November 2017.

35. Nirajkumar C Mehta, Dr. Dipesh D Shukla, Comparison of Life Cycle for Various Refractory Materials of Induction Melting Furnace Wall under Thermal Fatigue Loading Conditions", International Journal of Advance Engineering and Research Development, e-ISSN (O): 2348-4470, p-ISSN (P): 2348-6406, Volume 5, Issue 01, January 2018.

36. Patil Kaushal, Makwana Arjunsinh, Arab Mohammadazhar, Nirajkumar C Mehta, "Mathematically Advanced Computational Heat Transfer Analysis of Cylindrical and Spherical Induction Furnaces: Review", International Journal of Advance Engineering and Research Development, e-ISSN (O): 2348-4470, p-ISSN (P): 2348-6406, Volume 5, Issue 02, February 2018.

37. Ronik Varia, Sachin Vasani, Rahul Varma, Dr. Nirajkumar C Mehta, "Review of Solar Heating Furnace Development", International Journal of Advance Engineering and Research Development, e-ISSN (O): 2348-4470, p-ISSN (P): 2348-6406, Volume 5, Issue 03, March -2018 .

38. Rahul Waghela, Shreyas Parmar, Susmit Vasava, Dr. Nirajkumar C Mehta, "Review of Refractory Materials for Innovative Investigation and Testing", International Journal of Advance Engineering and Research Development, e-ISSN (O): 2348-4470, p-ISSN (P): 2348-6406, Volume 5, Issue 03, March -2018.

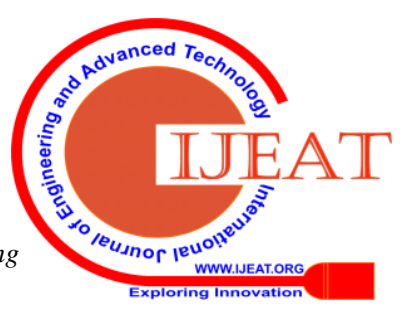

